\title{
Connecting to the Living History of Radiation Exposure
}

\author{
Jacob Hamblin ${ }^{1} \cdot$ Linda M. Richards ${ }^{1}$
}

Accepted: 1 February 2021 / Published online: 20 April 2021

(c) The Author(s), under exclusive licence to Springer Nature B.V. 2021

The largest radiation releases (I-131) studied by the government require the smallest health remedy. One tiny, inexpensive thyroid pill taken daily for the rest of your life; not life threatening. This is the most unimpactful radionuclide. It was chosen in order to show "it is not as bad as you think it is." Not like the hundreds of other radionuclides released to the public that cause leukemia, cancer, spontaneous abortion, birth defects, and sterility. The things that are still happening to someone like me.

Patricia Hoover, Hanford Downwinder (2018) ${ }^{1}$

The lived experience of contamination to our bodies, and the consequent generation of sickness and disease, is fraught with contested ideas about memory, science, authority, expertise, and the values we associate with life itself (Parry 2010; Steingraber 1997). In the latter half of the twentieth century, exposure to radiation created flourishing research fields in health physics and radiation biology, while also creating identities for some as "downwinders" who attributed their illnesses to living down-wind, down-river, or down-stream from a nuclear site (Fox 2014). The Hanford Nuclear Reservation Litigation, or the "Downwinders Case," remains one of the most controversial legal struggles in the history of atomic energy. It raised scores of environmental, scientific, civil rights, health, and legal questions. It focused on the chemical separation plant at Hanford, Washington, built during the Second World War to extract plutonium from spent uranium. The facility is one of the earth's most contaminated sites due to groundwater seepage, river pollution, and atmospheric discharges (Gerber 1992; Power 2008). The legal case, begun in 1990, consolidated thousands of plaintiffs who alleged that Hanford's environmental contamination was responsible for health problems, specifically thyroid disease, over a wide area that included several US states (Pritikin 2020). As significant a site as Hanford was (and

\footnotetext{
1 Patricia Hoover, remarks at research workshop, "Telling the Stories of Radiation Exposure," Oregon State University, Corvallis, Oregon, June 21, 2018.

Linda M. Richards

linda.richards@oregonstate.edu

Jacob Hamblin

jacob.hamblin@oregonstate.edu

1 School of History, Philosophy, and Religion, Oregon State University, Ballard Extension Hall 330B, 2591 SW Campus Way, Corvallis, OR 97331, USA
} 
is), the issues surrounding it were not unique. Similar scientific controversies, social justice concerns, and environmental consequences emerged in other contexts and other countries in the latter half of the twentieth century (Cianciolo 2015; Kushinskaya 2014; Shrader-Frechette 2013; Brown 2013; Brugge et al. 2006; Makhijani et al. 1995).

What is at stake when researching and narrating these histories of radiation exposure? On June 21-22, 2018, as part of a National Science Foundation grant, we convened a unique workshop at Oregon State University in Corvallis to draw a range of voices together to answer this question. ${ }^{2}$ The workshop focused on historical research, and it invited collaboration from several different academic fields while also reaching out to advocacy organizations to engage them directly in historical work. The above broad question, posed in the workshop's call for papers, was intended to provoke discussion among scholars, activists, and other citizens about the many challenges in researching, writing, or talking about past exposures to radiation. The histories of so-called "Downwinders" are contentious, in part because of the litigation and also due to continued scientific controversy. Yet the story must be told, and we must face the challenge. But how?

We initially prioritized inclusion of a diversity of voices and a range of narratives, believing that too intense a focus could blind us. With every narrowing on a focal point, essential pieces of other stories may be lost. ${ }^{3}$ What if, as Patricia Hoover warned us, the most pressing issues are unknowingly erased, even in the history of science, if we only look to science and the law for answers? She shared her painful experiences of sickness and long, drawn-out legal battles. She further noted the feeling of abandonment and betrayal felt by survivors who trusted their governments and academic experts. Many of the workshop participants were scholars, but some came keen to tell stories differently, as victim advocates or activists. They wondered whether their efforts would find respect among academics, or if we would defer instead to the hallowed process of peer review - the same process that many of them believe lent authority to published scientific work that allowed them to be exposed to harmful doses of radiation. They wondered whether we would deem them unscholarly, consider them biased activists rather than engaged witnesses, or listen to them at all.

We have begun to listen. And we also continue to care about the process of peer review in our scholarship. Not all workshop participants ended up writing essays for this special issue, but their voices carried us far in our discussions of unrepresented voices in extant historical narratives. For example, Desmond Doulatram, of the nonprofit REACH-MI (Radiation, Exposure, Awareness, Crusaders for Humanity-Marshall Islands), pointed out the history of exposure, betrayal, and empty promises experienced by people who lost their lands and lifeways due to trusting that their sacrifice would be "for the good of mankind." Yet he also made clear that

\footnotetext{
2 "Reconstructing Nuclear Environments and the Downwinders Case," National Science Foundation Award \#1734618.

3 We follow here the perspective pervasive among public historians and museum specialists that learning to listen to a range of actors is a way of sharing authority within historical narratives (McLean 2011).
} 
such disproportionate health impacts run in parallel with the lack of representation of intergenerational harm to the Marshallese within academic discourse, a point that is pertinent to indigenous peoples in other parts of the world as well. ${ }^{4}$ Similarly, Laureen Nussbaum and Patricia Hoover recalled their experiences developing a scientific health survey that found an excess of illness, in direct conflict with government conclusions that thyroid cases were not in excess (Nussbaum et al. 2004). To Nussbaum and Hoover, their work validated victims' claims while demonstrating the need for large scale epidemiological studies that should be followed by remedial actions. Together they voiced their frustrations at the use of scientific work to minimize the appearance of harm to those living near Hanford Nuclear Reservation.

One of our workshop's lessons was that, however we tell the stories of radiation, we need to find ways to foster and sustain dialogue among those continually affected. Helen Jaccard, with the Veterans for Peace Golden Rule Project, shared her sobering and stunning interviews with Japanese mothers after the Fukushima disaster of 2011. In Japan, some mothers were shamed by health professionals and told their concerns were imagined. They were told they are overly "radiosensitive" and that their concerns created additional emotional strife. Those who suffered were told they were the agents of their own suffering. ${ }^{5}$ Historian Britt Dahlberg highlighted how art can be a window into discourse of repair, responsibility, and resiliency. Her presentation, "Engaging Toxicity in Context: Asbestos, Oral History, Theater, and the Grounds for Dialogue," highlighted ways that the asbestos story compared to radiation exposure, and she drew attention to a creative model of supporting action for cleanup and environmental justice using art in a community affected by industrial collapse and pollution. ${ }^{6}$

The essays in this peer-reviewed special issue highlight the multiple ways of telling stories of radiation exposure; they include stories about Japan, Australia, the United States, the Canadian Arctic, and more, and they probe the framing of major incidents such as Three Mile Island, Chernobyl, and Fukushima. All the essays included here are by authors who participated in our work at Oregon State University and have benefited from hearing not only from scientists but also from those whose lives were directly affected by the history of radiation exposure. The academic environment challenges the essential ethical question of how to stay true to the many needs of exposed populations. By linking these authors together in this special issue, we embrace a fuller perspective, but we are also keenly aware of what voices are absent. The lack of radiation-exposed populations in this special issue,

\footnotetext{
${ }^{4}$ REACH-MI's work focuses not only on the continuing legacy of nuclear testing, but also a range of important issues such as climate change, ocean advocacy, and sustainable communities (https://www. reach-mi.org).

5 The Veterans For Peace Golden Rule Project's current advocacy work is tied to the historical era of nuclear testing but also includes peace activism (https://www.vfpgoldenruleproject.org). Related organizations, such as Beyond Nuclear, have broadened that activism to include criticism of civilian uses of nuclear energy as well (http://www.beyondnuclear.org).

${ }^{6}$ Dahlberg's public history work was an example of efforts to reexamine the contested histories of chemical exposures while connecting to a variety of audiences. It was part of her work at the Science History Institute's Center for Applied History (https://www.sciencehistory.org).
} 
beyond this brief introduction, is a testament to their ongoing suffering and disappointment. However, many of our authors have worked to portray how these communities' suffering came to be. It may be that, in the future, we will find a way to move from this seed of inclusion to a place where the radiation exposed can represent themselves and speak in their own voices.

Opening the special issue are two essays on contested interpretations of scientific data among victims of radiation exposure. Mary X. Mitchell shows how, in the aftermath of the Three Mile Island accident, citizen activists centered their scientific inquiry on the suffering, living world. In litigation, plaintiffs tried to make sense of their unexplained experiences and observations and substantiate radiation exposure with evidence from their own bodies. After failing to convince government agencies to launch serious studies of their cases, activists turned to citizen science in collaborative, expert scientific testimony in ongoing personal injury cases. Cynthia Folkers highlights inadequacies in extant scientific studies in an essay exploring the longstanding pattern of minimizing harm from radioactivity. Her provocative article suggests that risks to women, children, and pregnancy have been devalued through institutional silence and misapplication of science. She argues that correcting the narrative is not only important to understanding the history of biological effects, but also to future decision-making about a range of issues such as climate change mitigation and future energy sources.

We follow these with two essays that address perception and invisibility. Jonathan Luedee is concerned with perceptibility in science, specifically, assessments of radioactive contamination to human and non-human bodies. He draws from records of scientific institutions and health officials in Canada and the United States as they studied exposure levels in northern communities, often based on bioaccumulation in caribou. He tells the story of a series of bioenvironmental investigations in the 1950s and 1960s, showing how scientists mapped the spatial and temporal boundaries of radioactive exposures (or body burdens) in northern communities. Taking an approach that emphasizes visual culture, N. A. J. Taylor shows us multiple invisibilities in telling the stories of radiation in Oceania. One is that of biological life in settler colonial artistic representations, in response to the British nuclear tests at Maralinga. Another is the relative absence of Oceania generally in discussions of global nuclear history and culture. Taylor urges us to consider what the irradiation of biological life in Antipodean nuclear art can tell us about broader efforts of telling stories of radiation exposure.

We end with two essays focusing on depictions of radiation exposure in the scientific literature. Sumiko Hatakeyama offers an analysis of the role of atomic bomb survivors (hibakusha) as witnesses - not just as we typically understand the word, but as instruments of science. She shows us how survivors' inscribed bodies have, ever since the bombings of Hiroshima and Nagasaki, narrated what it means to be exposed to radiation. Focusing on two decades after the mid-1950s, Hatakeyama highlights how new methods, practices, and technologies allowed scientists to investigate chromosomal aberrations as a way to study radiation exposure and human risk. The decision to "let chromosomes speak" became not only a scientific approach but also an institutional strategy of engaging and publicizing contested science. David Hecht offers an essay on the treatment of radiation risks in public 
discourse, particularly science writing in the early years of the Cold War. He shows us how literary forms - such as war reporting, travel memoir, and detective fictionpermeated accounts of radiation exposure. Hecht suggests that such forms provided tools for writers to overcome some of the inherent challenges of communicating radiation risks. These forms lent authority to the texts while also laying down narratives, showing us-uncomfortable as it may seem-just how much of science is storytelling.

The Journal of the History of Biology has been an important outlet for enriching the historiography of the twentieth-century history of radiobiology, health physics, dosimetry, and genetics (Lindee 1992; Bocking 1995; Creager 2006; de Chadarevian 2006; Gaudillière 2006; Rader 2006; Santesmases 2006; Hamblin 2007; Goldstein and Stawkowski 2015). ${ }^{7}$ We hope this special issue will aid us in thinking through what the stakes have been in the framing of historical narratives. We present a range of perspectives that draw attention to the ways nuclear narratives emerge-in forums as widely divergent as legal cases, activism, scientific institutions, literature, and art. The biological effects of radiation exposure are deeply contested, and this is likely to continue. Our goal is not to reinforce existing frameworks, such as legal decisions or government policies, but rather to highlight what narrative framings accomplish and commit once again to scrutinizing them with rigorous research, varied approaches, and, above all, listening to those whose lives were most affected by exposure.

\section{References}

Bocking, Stephen. 1995. Ecosystems, Ecologists, and the Atom: Environmental Research at Oak Ridge National Laboratory. Journal of the History of Biology 28: 1-47.

Brown, Kate. 2013. Plutopia: Nuclear Families, Atomic Cities, and the Great Soviet and American Plutonium Disasters. New York: Oxford University Press.

Brugge, Doug, Timothy Benally, and Esther Yazzie-Lewis, eds. 2006. The Navajo People and Uranium Mining. Albuquerque, NM: University of New Mexico Press.

Cianciolo, Patricia K. 2015. Compensating Nuclear Weapons Workers and their Survivors: The Case of Fernald. Michigan Family Review 19 (1): 51-72.

Creager, Angela N.H. 2006. Nuclear Energy in the Service of Biomedicine: The US Atomic Energy Commission's Radioisotope Program, 1946-1950. Journal of the History of Biology 39: 649-684.

de Chadarevian, Soraya. 2006. Mice and the Reactor: the "Genetics Experiment" in 1950s Britain. Journal of the History of Biology 39: 707-735.

Fox, Sarah Alisabeth. 2014. Downwind: A People's History of the Nuclear West. Lincoln, NB: University of Nebraska Press.

Gaudillière, Jean-Paul. 2006. Normal Pathways: Controlling Isotopes and Building Biomedical Research in Postwar France. Journal of the History of Biology 39: 737-764.

Gerber, Michele Stenehjem. 1992. On the Home Front: The Cold War Legacy of the Hanford Nuclear Site. Lincoln, NB: University of Nebraska Press.

Goldstein, Donna M., and Magdalena E. Stawkowski. 2015. James V. Neel and Yuri E. Dubrova: Cold War Debates and the Genetic Effects of Low-Dose Radiation. Journal of the History of Biology 48: 67-98.

\footnotetext{
7 See especially the 2006 Journal of the History of Biology special issue "Radiobiology in the Atomic Age" edited by Angela N. H. Creager and María Jesús Santesmases.
} 
Hamblin, Jacob Darwin. 2007. "A Dispassionate and Objective Effort:" Negotiating the First Study on the Biological Effects of Atomic Radiation. Journal of the History of Biology 40: 147-177.

Kushinskaya, Olga. 2014. The Politics of Invisibility: Public Knowledge about Radiation Health Effects after Chernobyl. Cambridge, MA: MIT Press.

Lindee, M. Susan. 1992. What Is a Mutation? Identifying Heritable Change in the Offspring of Survivors at Hiroshima and Nagasaki. Journal of the History of Biology 25: 231-255.

Makhijani, Arjun, Howard Hu, and Katherine Yih. 1995. Nuclear Wastelands: A Global Guide to Nuclear Weapons Production and its Health and Environmental Effects. Cambridge, MA: MIT Press.

McLean, Kathleen. 2011. Whose Questions, Whose Conversations? In Letting Go? Sharing Historical Authority in a User-Generated World, ed. Joseph N Newland, 70-79. Philadelphia, PA: Pew Center for Arts and Heritage.

Nussbaum, Rudi H., Patricia P. Hoover, Charles M. Grossman, and Fred D. Nussbaum. 2004. Community-Based Participatory Health Survey of Hanford, WA, Downwinders: A Model for Citizen Empowerment. Society \& Natural Resources 17(6): 547-559.

Parry, Joy. 2010. Sensing Changes. Technologies, Environments, and the Everyday, 1953-2003. Seattle, WA: University of Washington Press.

Power, Max S. 2008. America's Nuclear Wastelands: Politics, Accountability and Cleanup. Pullman, WA: Washington State University Press.

Pritikin, Trisha. 2020. The Hanford Plaintiffs: Voices from the Fight for Atomic Justice. Lawrence, KS: University Press of Kansas.

Rader, Karen. 2006. Alexander Hollaender's Postwar Vision for Biology: Oak Ridge and Beyond. Journal of the History of Biology 39: 685-706.

Santesmases, María Jesús. 2006. Peace Propaganda and Biomedical Experimentation: Influential Uses of Radioisotopes in Endocrinology and Molecular Genetics in Spain (1947-1971). Journal of the History of Biology 39: 765-794.

Shrader-Frechette, Kristin. 2013. Technocratic Threats to Human Rights: Pollution Wolves in Scientific Sheep's Clothing: Why Environmental-Risk Assessors and Policy-Makers Ignore the "Hard Issues" of the Human Rights of Pollution Victims. In Human Rights: The Hard Questions, ed. C. Holder and D. Reidy, 246-268. New York: Cambridge University Press.

Steingraber, Sandra. 1997. Living Downstream: An Ecologist Looks at Cancer and the Environment. London: Virago.

Publisher's Note Springer Nature remains neutral with regard to jurisdictional claims in published maps and institutional affiliations. 